\title{
Increased expression of T helper 17 cells and interleukin-17 in atopic dermatitis: a systematic review and meta-analysis
}

\author{
Yujie Mao $^{1,2 \#}$, Chao Yang ${ }^{1,2 \#}$, Lina Tang ${ }^{1,2}$, Gang Liu ${ }^{1,2}$, Liping Cheng ${ }^{2,3}$, Mingyi Chen $^{1,2}$ \\ ${ }^{1}$ Institute of Dermatology and Venereology, Sichuan Provincial People's Hospital, University of Electronic Science and Technology of China, \\ Chengdu, China; ${ }^{2}$ Chinese Academy of Sciences, Sichuan Translational Medicine Research Hospital, Chengdu, China; ${ }^{3}$ Geriatric Cardiovascular \\ Ward 3, Sichuan Provincial People's Hospital, University of Electronic Science and Technology of China, Chengdu, China \\ Contributions: (I) Conception and design: Y Mao, C Yang, L Cheng, M Chen; (II) Administrative support: L Tang; (III) Provision of study materials \\ or patients: Y Mao, C Yang, L Tang, G Liu; (IV) Collection and assembly of data: Y Mao, C Yang, L Cheng, M Chen; (V) Data analysis and \\ interpretation: All authors; (VI) Manuscript writing: All authors; (VII) Final approval of manuscript: All authors. \\ \#These authors contributed equally to the work. \\ Correspondence to: Mingyi Chen; Liping Cheng. Sichuan Provincial People's Hospital, University of Electronic Science and Technology of China, No. \\ 32, West 2, Section 1 Ring Road, Qingyang District, Chengdu, China. Email: chenmingyi12342021@163.com; A809854879@163.com.
}

\begin{abstract}
Background Atopic dermatitis (AD) is a chronic inflammatory skin disease with genetic susceptibility and recurrent attacks. Research examining the etiology of this disease has mainly focused on environmental factors and immunity, with immune disorders believed to be the main factor in the occurrence and development of AD. While some studies have demonstrated that increased proportion of T helper 17 (Th17) cells in the lesions of specific dermatitis mouse models, the expression of Th17 cells and interleukin (IL)-17 in patients with $\mathrm{AD}$ remains controversial.
\end{abstract}

Methods: Related literatures were retrieved from English databases including PubMed, Embase, and OvidMedline. Literatures published from the establishment of the database to April 2021 were identified using the following keywords: AD, T helper cell 17 (Th17 cell), and interleukin 17 (IL-17). Review Manager5.3 software was adopted for meta-analysis.

Results: A total of 8 studies, involving 1,147 subjects, related to the pathogenesis of AD were included in this meta-analysis. The analysis revealed that the expression of Th17 cells in patients with AD was higher than that in healthy patients $(\mathrm{P}<0.00001)$, and the serum expression of IL-17 was also elevated in patients with $\mathrm{AD}$ compared to healthy participants $(\mathrm{P}=0.0001)$.

Discussion: A total of 8 publications related to the pathogenesis of $\mathrm{AD}$ were analyzed. The meta-analysis found that patients with AD had higher expressions of Th17 cells and IL-17 compared to healthy subjects, suggesting that AD may be related to Th17 cells and IL-17.

Keywords: Atopic dermatitis (AD); T helper cell 17 (Th17 cell); interleukin 17 (IL-17); meta-analysis; correlation

Submitted Nov 15, 2021. Accepted for publication Dec 17, 2021.

doi: 10.21037/apm-21-3590

View this article at: https://dx.doi.org/10.21037/apm-21-3590

\section{Introduction}

Atopic dermatitis (AD) is a recurrent and genetically susceptible skin disease. The age of onset is young with a prolonged duration of illness that can result in significant skin damage. $\mathrm{AD}$ can often be accompanied by other allergic conditions such as asthma and allergic rhinitis (1). The clinical characteristics of the disease can be divided into 3 different stages, namely, infancy, childhood, and adulthood. Infant $\mathrm{AD}$ affects children aged 1 month to 2 years old and the clinical manifestations include exudative skin lesions such as papules and blisters, and dry skin. Childhood AD is mostly acquired in infancy, and can manifest as eczema and itchy skin features. In adulthood, most patients present with localized dry skin damage (2). The treatment methods 
are mainly symptomatic treatments such as antipruritic, moisturizing, and moisturizing (3).

Due to the high incidence and recurrence rate of atopic dermatitis, which seriously affects the physical and mental health of patients, it has caused widespread concern in the dermatology community. In order to find effective treatments, domestic and foreign research experts have conducted a large number of comprehensive and indepth studies on the etiology and pathogenesis of atopic dermatitis, and have achieved certain results. Studies have found that genetic susceptibility, impaired skin barrier function, immune system disorders, and microbial superantigens play an important role in the pathogenesis of atopic dermatitis, but there is still no point of view that can fully clarify the pathogenesis of atopic dermatitis (4-6). Some studies have suggested that changes to the internal and/or external environment may result in impaired skin barrier function. Other reports have suggested that immune system dysfunction is the main cause of $\mathrm{AD}$, especially the imbalanced expression of T helper 1 cells (Th1 cells) and $T$ helper 2 cells (Th2 cells) (7-9).

Subsequent studies identified T helper 17 cells (Th17 cells) as a key factor in the pathogenesis of AD. There is an imbalance of Th17/Treg cells in AD patients, and the proportion of Th17 cells in the peripheral blood of patients is significantly increased (10). Th17 cells are closely related to the autoimmune response. The generation and differentiation of Th17 cells largely depends on transforming growth factor- $\beta$ (TGF- $\beta$ ) and other cytokines (11). Initial $T$ cells can be induced to differentiate into Th17 cells and promote the secretion of related cytokines under the stimulation of TGF- $\beta$ and interleukin 6 (IL-6) (12). Interleukin 23 (IL-23) can maintain the expression levels of Th17 cells, as well as participate in and promote interleukin 17 (IL-17)-mediated inflammatory response (13). IL-17 is mainly secreted by Th17 cells, which is the main effector factor of Th17 cells involved in inflammatory response. In addition, Th17 cells secrete IL-21, IL-22, and other cytokines. IL-17 participates in the inflammatory response by binding to the IL-17 receptor (IL-17R) to form immune complexes. IL-17 can also induce the production of a variety of inflammatoryrelated cytokines and aggravate the inflammatory response through its combined action. Furthermore, IL-17 is a key factor in neutrophil recruitment, activation, and aggregation (14). Therefore, IL-17 plays an important role in innate immunity and immune defense. However, it can also mediate an excessive immune response which does not have protective properties, but rather, increases the risk of immune pathology and autoimmune responses. Studies have shown that the levels of IL-17 and other inflammatory factors in the peripheral blood of patients with Alzheimer's disease are significantly increased (15).

To date, numerous observational studies have examined the expression levels of Th17 cells and IL-17 in patients with $\mathrm{AD}$. However, there is no research using systematic evaluation methods to comprehensively evaluate the changes of immune cells and factor levels in AD patients. To clarify the relationship between $\mathrm{AD}$ and the expression of Th17 cells and IL-17, this meta-analysis was conducted to comprehensively and systematically evaluate the available observational studies. Furthermore, this study examined the immune-related pathogenic factors of $\mathrm{AD}$, thereby providing important data for the development of future treatment strategies for patients with $\mathrm{AD}$. We present the following article in accordance with the PRISMA reporting checklist (available at https://dx.doi. org/10.21037/apm-21-3590).

\section{Methods}

\section{Literature retrieval strategy}

A comprehensive and systematic literature study was conducted based on the Cochrane Review Manual of Intervention System. The PubMed, Embase, and OvidMedline databases were searched for articles relating to patients with $\mathrm{AD}$ and $\mathrm{AD}$ pathogenesis. The specific search terms used in the keywords and medical titles were as follows: "AD”, "interleukin-17 (IL-17)", "T helper cell 17 (Th17 cell)", and "correlation".

\section{Inclusion and exclusion criteria}

The following inclusion criteria were applied: (I) clinical case-control studies examining the expression of Th17 cells in the peripheral blood and/or serum IL-17expression in patients with $\mathrm{AD}$; (II) patients in the case group had confirmed diagnoses of $\mathrm{AD}$ according to the clinical diagnostic criteria, and the control group were healthy persons; (III) the observation indicators included Th17 expression levels in the peripheral blood and IL-17 expression levels in the serum; and (IV) no experimental data was missing, the sample size was accurate, and the inter-group data of the subjects were complete.

The following exclusion criteria were applied: (I) 
publications that were not clinical case-control studies, including reviews, case reports, animal experiments, and intervention experiments; (II) duplicate literature; (III) literature that did not mention the specific diagnostic criteria for AD; (IV) studies examining other systemic diseases, immune-related diseases, or other skin condition of the observed subjects; (V) literature involving subjects who had received glucocorticoid, immunosuppressant, or other treatments within a 2-week period; and (VI) literature published in the Chinese language.

\section{Literature screening}

The two researchers independently screened the titles and abstracts according to the inclusion and exclusion criteria, and data extraction and quality evaluation were performed. Any discrepancies between the two researchers were resolved by discussion and consultation with a third researcher. The full text articles were then retrieved for data extraction. NoteExpress 2.0 was used to manage the articles and duplicate literatures were deleted.

\section{Data extraction}

The two researchers independently extracted relevant information from all eligible studies, using predefined data extraction tables. The information collated included author, year of publication, sample size, age, country, gender, degree of disease, and course of disease. The diagnostic criteria of atopic dermatitis $(\mathrm{AD})$ were used. In the case of missing data, the author of the original publication was contacted to obtain the relevant information. For data that could not be obtained, relevant transformations were performed based on the Cochrane evaluation manual, such as calculation of the standard deviation of continuous data.

\section{Quality evaluation}

To improve the quality of the reviewed literature, quality assessments were conducted according to the "Risk assessment of bias" recommended in version 5.3 of the Cochrane System's Review Manual. The evaluation included the following seven items: (I) random method; (II) concealment allocation; (III) blinding implementation of patients and researchers; (IV) evaluation of the effect of the blind method; (V) integrity of the results; (VI) credibility of the survey results; and (VII) other bias. "Meet" represents a small bias, and "does not meet" refers to a high degree of bias. Based on the scoring of the four levels, literature with scores of 1-3 points are regarded as low quality, and literature with 4-7 points are regarded as high quality.

\section{Data analysis}

A forest map clearly shows the research results of various studies and combines the corresponding confidence intervals from each study. This study used $\mathrm{I}^{2}$ statistics for heterogeneity analysis. When $\mathrm{I}^{2}<50 \%$ and $\mathrm{P}>0.05$, the fixed effects model was selected for meta-analysis as there is no statistical heterogeneity among the tests. When $\mathrm{I}^{2} \geq 50 \%$ and $\mathrm{P} \leq 0.05$, the random effects model was selected for metaanalysis as there is statistical heterogeneity among the tests. The combined effect of the two groups of evaluation index data was used to determine the odds ratio (OR) value and its $95 \%$ confidence interval (CI). For results with large heterogeneity, the article by article exclusion method was used to explore the possible source of heterogeneity, and the sensitivity of the results was analyzed. This study used (I) to change the inclusion criteria; (II) to exclude low-quality studies; (III) to use different statistical methods/models for the same data analysis, and other processes, to conduct a sensitivity analysis of the included literature. If the number of randomized controlled trial (RCTs) of an indicator is greater than or equal to 5 , publication bias was evaluated and the funnel plot method was applied.

\section{Statistical analysis}

The Review Manager 5.3 software (provided by Cochrane Collaboration) was used for statistical analyses and a $\mathrm{P}$ value $<0.05$ was considered statistically significant.

\section{Results}

\section{Literature retrieval}

In this study, a total of 1,694 related literatures were retrieved, of which 1,063 were obtained from the PubMed database, 452 were retrieved from the Embase database, and 179 were retrieved from the Ovid-Medline database. A total of 1,298 repetitive articles were excluded. After reading the studies and abstracts, 345 articles that did not meet the inclusion criteria were excluded. By reading the full text, 35 articles were excluded. Finally, 8 articles (15-22) satisfied the inclusion criteria. Details of the literature screening 


\section{Identification of studies via databases and registers}
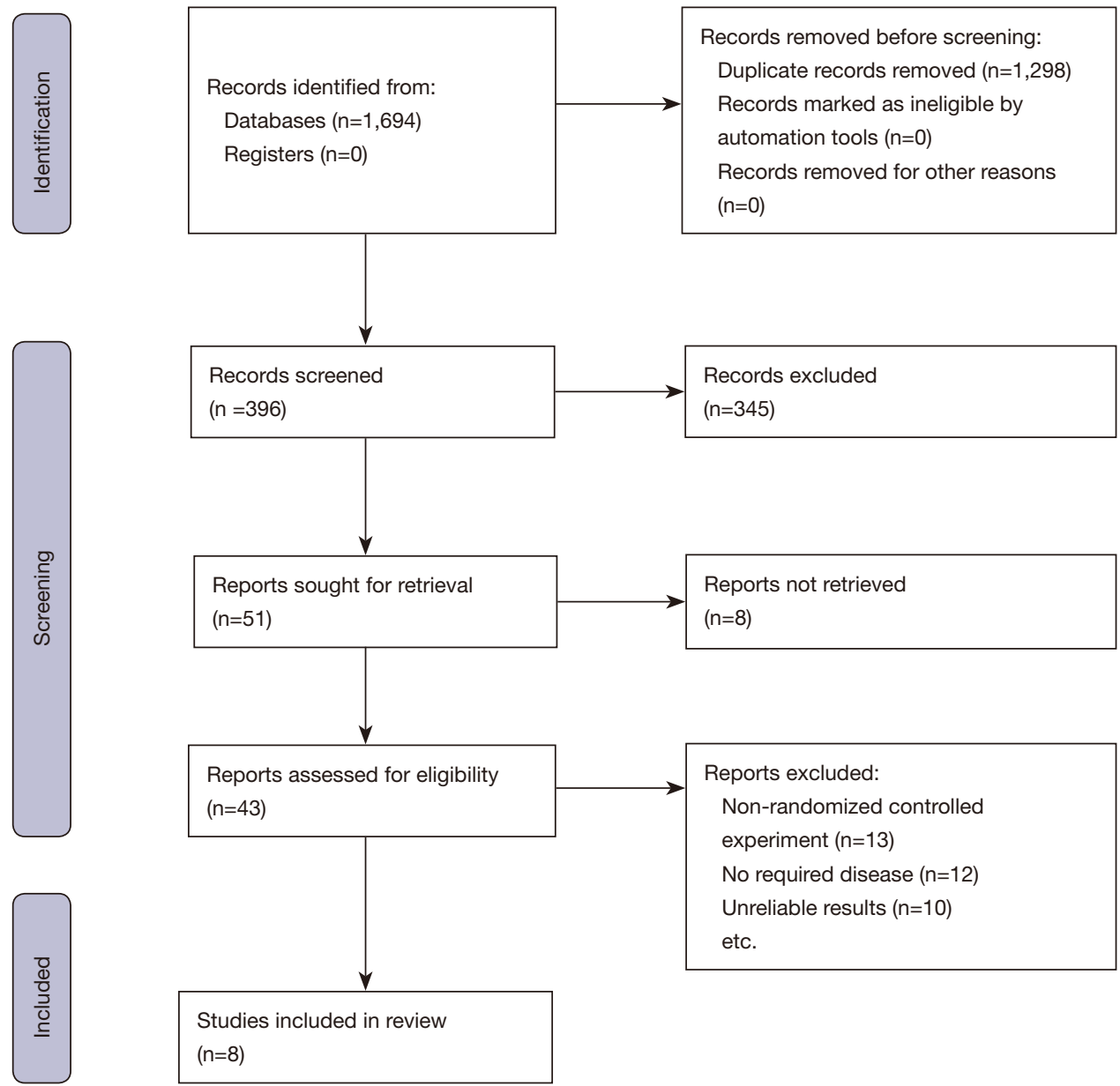

Studies included in review

$(n=8)$

Figure 1 A flow chart showing the literature retrieval process.

process are illustrated in Figure 1. The basic information of the included literature is shown in Table 1.

\section{Bias risk assessment of the included literature}

The Cochrane Handbook version 5.3 system evaluation manual was used to evaluate the bias risk of the 8 publications included in this study (Figures 2,3).

The quality of each included literature was evaluated using the Newcastle-Ottawa Scale (NOS) score (Table 2). All 8 literatures included in this meta-analysis had a low risk of bias and satisfied the requirements of follow-up analysis.

\section{Expression level of Th17 cells in patients with AD}

All 8 articles examined the expression of Th17 cells in patients with AD. There was homogeneity among the studies $\left(\mathrm{P}<0.00001, \mathrm{I}^{2}=100 \%\right)$ and the random effects model was used. The meta-analysis showed that there was a statistically significant difference in the content of Th17 cells in the serum of patients with AD compared with patients in the control group [mean difference $(M D)=2.67$; 95\% CI: 1.58 to $3.77 ; \mathrm{P}<0.00001$; Figure 4].

The Th17 cells in the patient's serum were taken as an indicator. The results shown by an inverted funnel 
Table 1 The basic information of the included literature

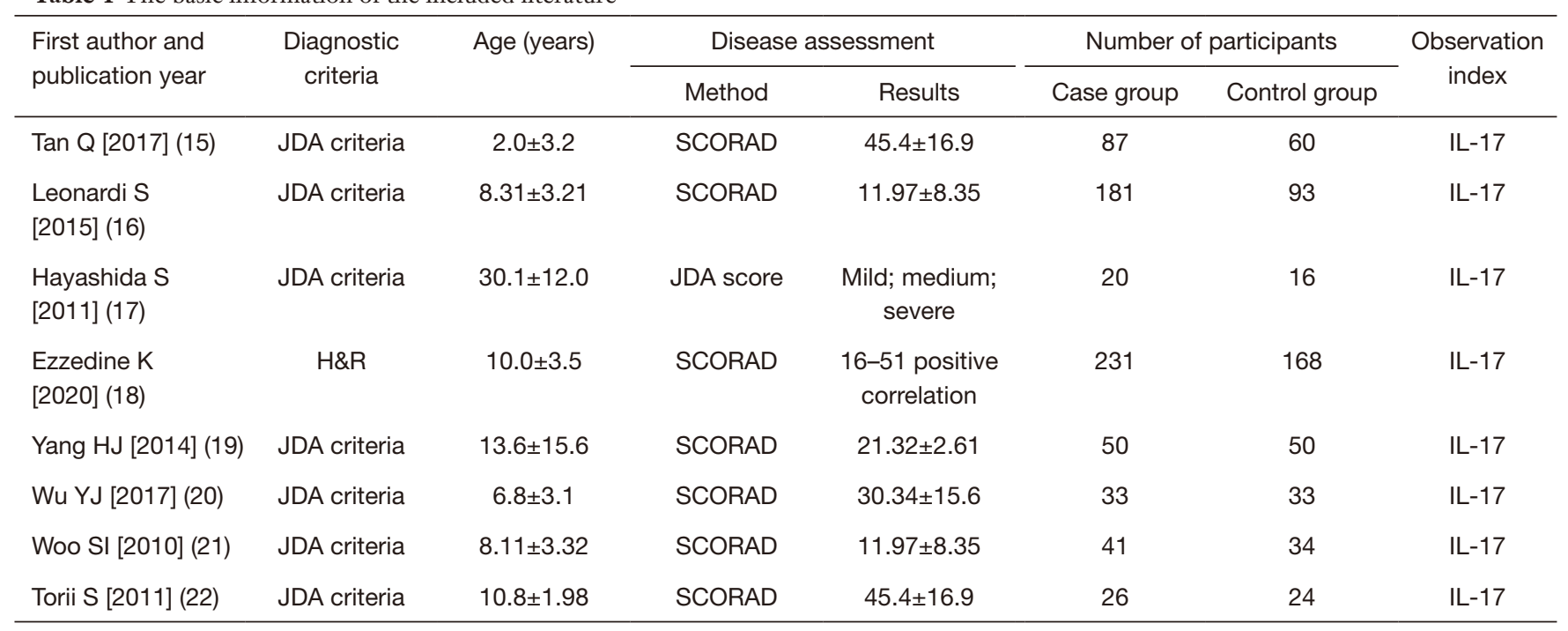

JDA, Japanese Dermatological Association; SCORAD, Scoring Atopic Dermatitis; IL, interleukin.

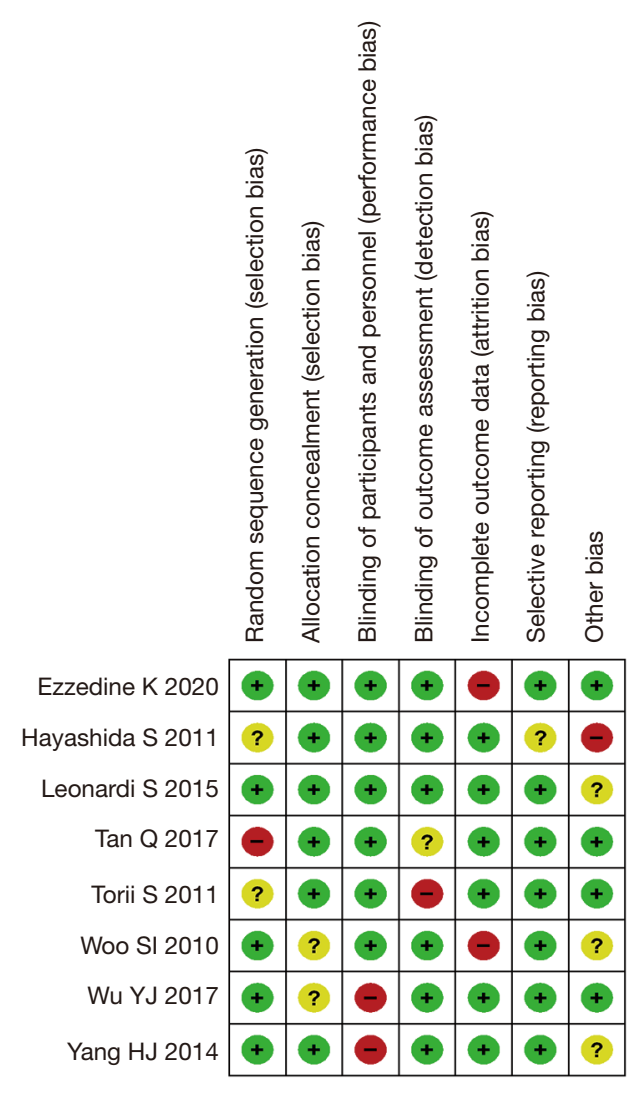

Figure 2 A literature bias risk assessment chart. diagram illustrated that the scattered points of the study subjects were roughly bottom-down funnel-shaped. In the horizontal axis direction, they were roughly symmetrically arranged; suggesting that the publication bias was not obvious, as shown in Figure 5.

\section{IL-17 expression level in patients with AD}

All 8 articles examined the serum IL-17 content. There was homogeneity among the studies $\left(\mathrm{P}<0.00001, \mathrm{I}^{2}=100 \%\right)$ and the random effects model was used. The results demonstrated that the serum IL-17 content was significantly different between patients with $\mathrm{AD}$ and control healthy subjects $(M D=14.51 ; 95 \%$ CI: 7.16 to $21.86 ; P=0.0001$; Figure 6).

The inverted funnel plot was approximately symmetrical, indicating that there was no obvious publication bias (Figure 7).

\section{Discussion}

At present, there is no specific medicine that can cure $\mathrm{AD}$ or reverse the course of the disease. Therefore, it is clinically hoped to reduce symptoms and delay the development of the disease through combined drug therapy, non-drug 


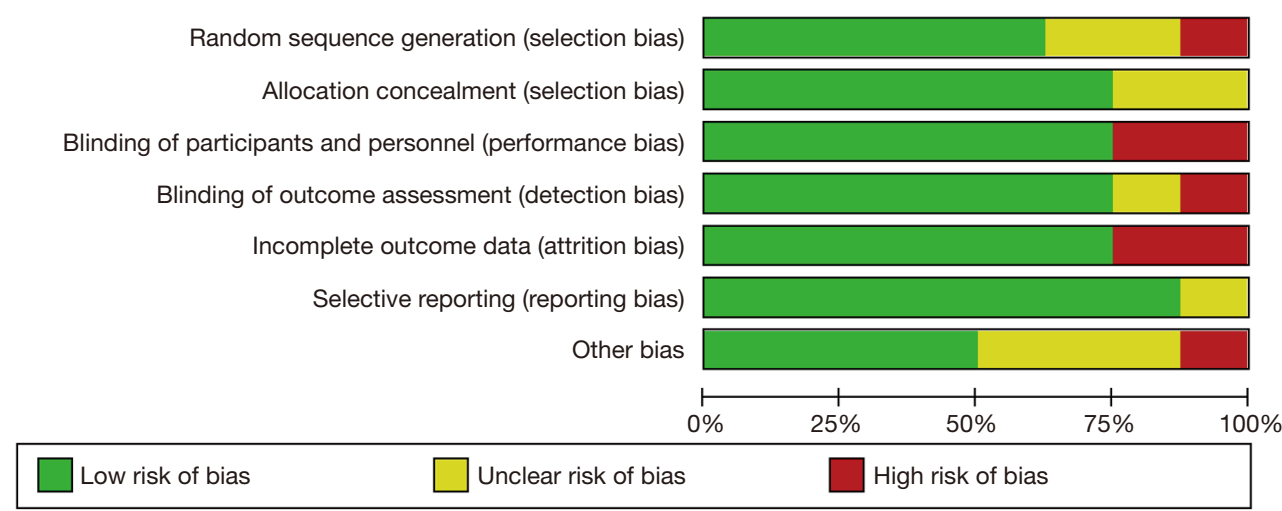

Figure $3 \mathrm{~A}$ bar chart showing the bias risk assessment of the included literature.

Table 2 The quality score of the included literature

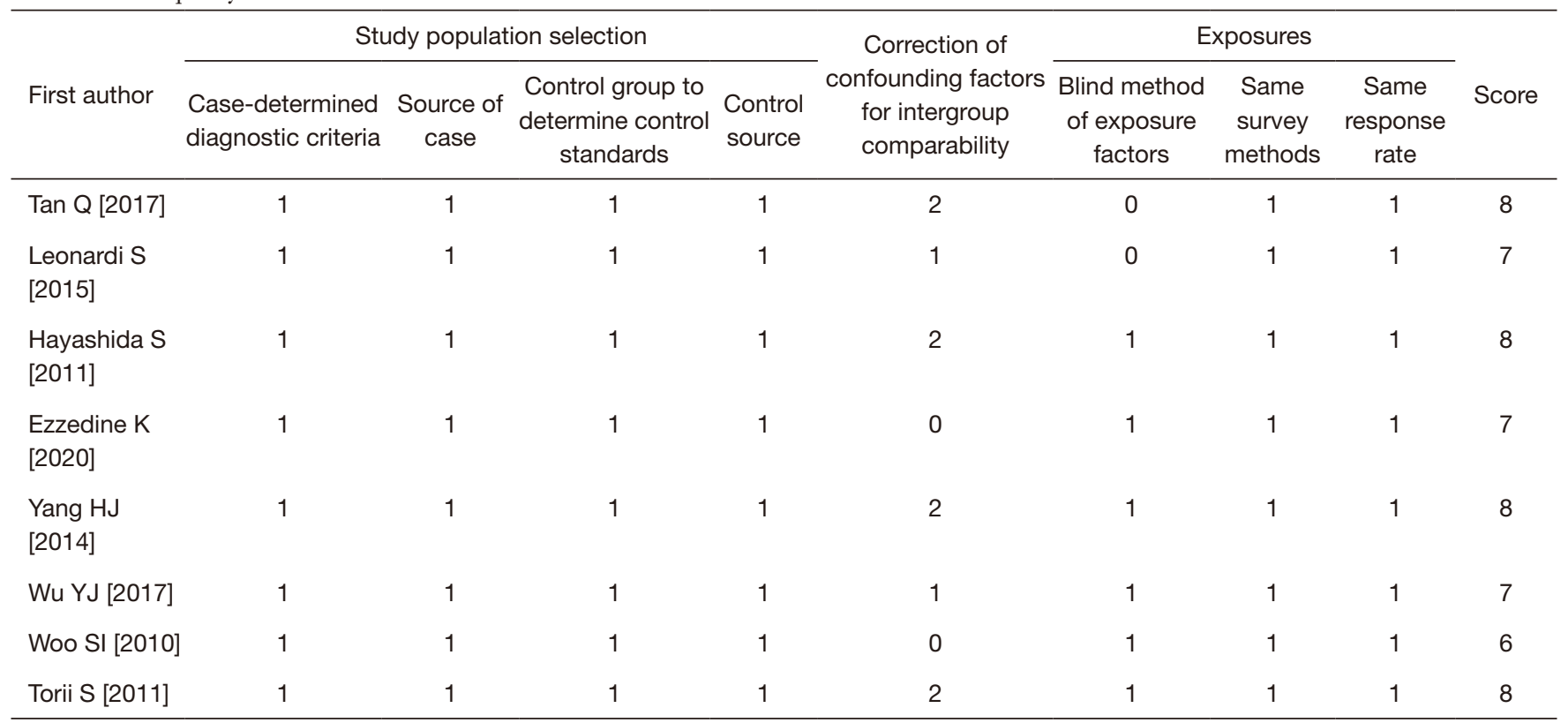

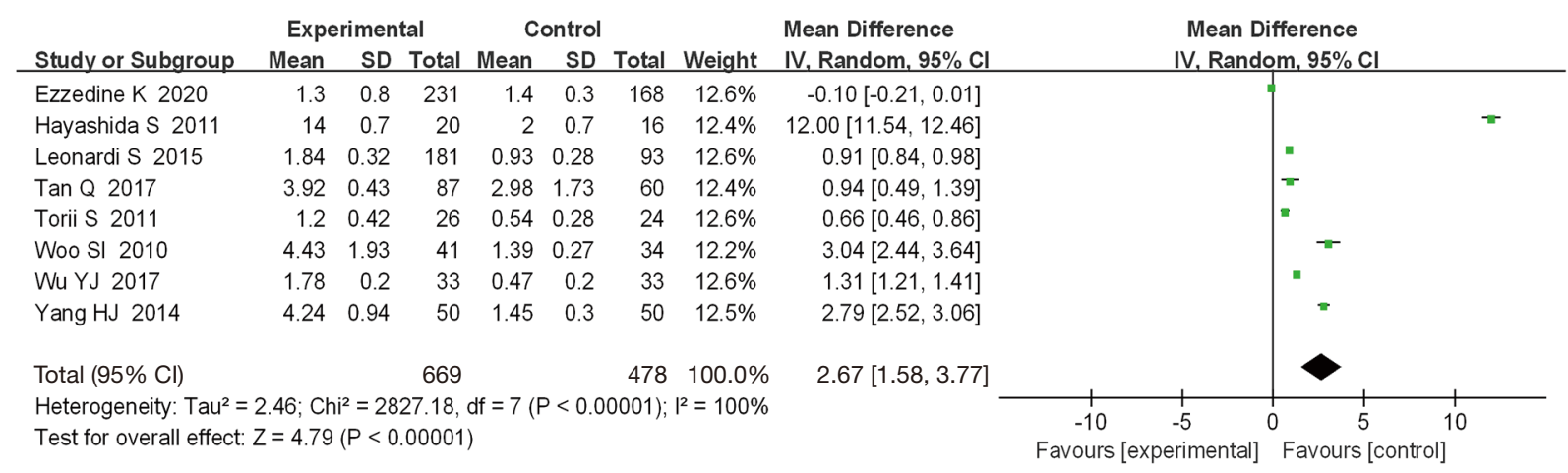

Figure 4 A forest map of the comparison of T helper 17 cells in the serum of patients with atopic dermatitis and control healthy subjects. 


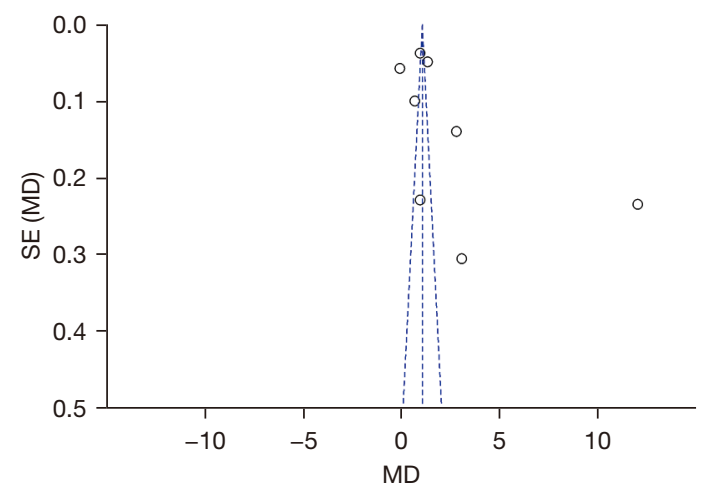

Figure 5 A funnel plot for the comparison of T helper 17 cells in the serum of patients with atopic dermatitis and control healthy subjects.

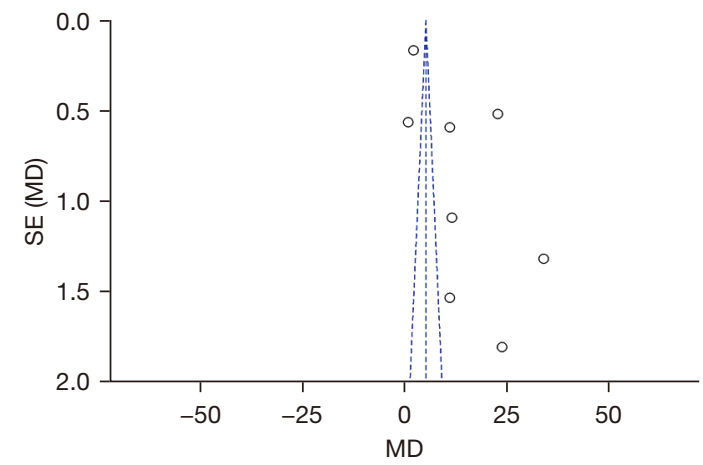

Figure 7 A funnel plot for the comparison of serum interleukin-17 levels in patients with atopic dermatitis and control healthy subjects.

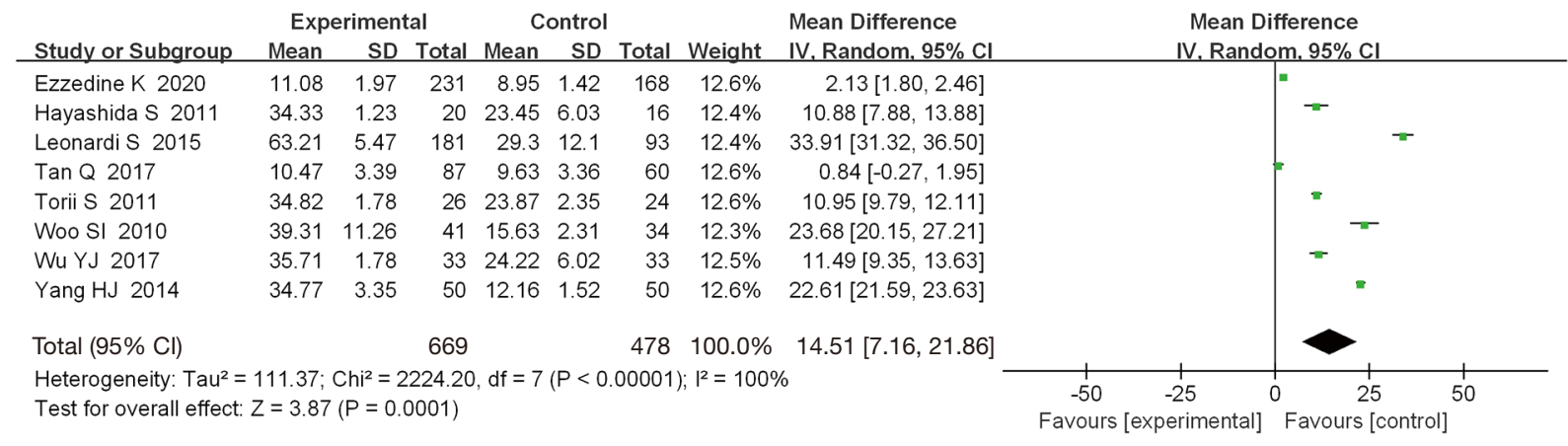

Figure 6 A forest map for the comparison of serum interleukin-17 levels in patients with atopic dermatitis and control healthy subjects.

therapy, and nursing intervention. Because individual differences are too large, drug treatment needs to be guided by a doctor in combination with individual circumstances to choose the most appropriate drug.

This meta-analysis demonstrated that the expression level of Th17 cells in patients with AD was significantly higher than that in healthy participants. Previous studies have shown that the imbalance of the Th1/Th2 cell network plays a crucial role in the immune pathogenesis of $\mathrm{AD}(23)$. In the acute phase, Th2 cells are dominant, while in the chronic phase, Th1 cells are dominant (24). In addition to the Th1/Th2 cell imbalance, CD4 ${ }^{+} \mathrm{T}$ cells, Th17 cells, and regulatory $\mathrm{T}$ (Treg) cells have also been shown to play an important role in the immune pathogenesis of $\mathrm{AD}$ (25). In general, Th17 cells promote the inflammatory response and Treg cells inhibit the inflammatory response. The key factor in the pathogenesis of many inflammatory and autoimmune diseases is the imbalance between the Treg cells and the inflammatory Th17 cells (26). In pathological and physiological conditions, Th17 and Treg cells also participate in positive and negative feedback regulation from various immune cells and cytokines during the immune response (27).

This meta-analysis revealed that the expression of IL17 in the serum of patients with AD was significantly higher than that in the healthy group. Skin barrier function plays an important role in the pathogenesis of $\mathrm{AD}$, and immune disorders are closely related to AD (28). IL17 is a pro-inflammatory factor produced by Th17 cells, which can activate immune cells, improve the immune response of $\mathrm{T}$ cells, and express pro-inflammatory factors and chemokines. IL-17 plays an important role in the generation of autoimmune diseases in the body. Indeed, IL-17 expression levels are elevated in psoriasis, systemic lupus erythematosus, and allergic rhinitis. IL-23 is a cytokine produced by dendritic cells and macrophages, 
and is important in the amplification of Th17 cells and the maintenance of the Th17 cell response. The serum levels of IL-17 and IL-23 in AD patients has been shown to be significantly higher than those in normal controls (29).

In conclusion, the pathogenesis of $\mathrm{AD}$ involves many aspects, with the main mechanism related to immune balance disorders. Among them, the imbalance of Th1/Th2 cells and Th17 cells is crucial to the inflammatory response in $\mathrm{AD}$.

\section{Conclusions}

This meta-analysis examined 8 studies and revealed that the expression level of Th17 cells and the levels of serum IL17 in patients with $\mathrm{AD}$ were significantly higher than those in healthy participants. Indeed, the pathogenesis of $\mathrm{AD}$ may be related to the expression of Th17 cells and IL-7.

\section{Acknowledgments}

Funding: None.

\section{Footnote}

Reporting Checklist: The authors have completed the PRISMA reporting checklist. Available at https://dx.doi. org/10.21037/apm-21-3590

Conflicts of Interest: All authors have completed the ICMJE uniform disclosure form (available at https://dx.doi. org/10.21037/apm-21-3590). The authors have no conflicts of interest to declare.

Ethical Statement: The authors are accountable for all aspects of the work in ensuring that questions related to the accuracy or integrity of any part of the work are appropriately investigated and resolved.

Open Access Statement: This is an Open Access article distributed in accordance with the Creative Commons Attribution-NonCommercial-NoDerivs 4.0 International License (CC BY-NC-ND 4.0), which permits the noncommercial replication and distribution of the article with the strict proviso that no changes or edits are made and the original work is properly cited (including links to both the formal publication through the relevant DOI and the license). See: https://creativecommons.org/licenses/by-nc-nd/4.0/.

\section{References}

1. Borok J, Matiz C, Goldenberg A, et al. Contact Dermatitis in Atopic Dermatitis Children-Past, Present, and Future. Clin Rev Allergy Immunol 2019;56:86-98.

2. Sidbury R, Kodama S. Atopic dermatitis guidelines: Diagnosis, systemic therapy, and adjunctive care. Clin Dermatol 2018;36:648-52.

3. Waldman AR, Ahluwalia J, Udkoff J, et al. Atopic Dermatitis. Pediatr Rev 2018;39:180-93.

4. Tsai HC, Wu R. Cholera toxin directly enhances IL17A production from human CD4+ T cells. J Immunol 2013;191:4095-102.

5. Takano S, Tsuboi K, Tomono Y, et al. Tissue factor, osteopontin, alphavbeta3 integrin expression in microvasculature of gliomas associated with vascular endothelial growth factor expression. Br J Cancer 2000;82:1967-73.

6. Andersen SS, Hvid M, Pedersen FS, et al. Proximity ligation assay combined with flow cytometry is a powerful tool for the detection of cytokine receptor dimerization. Cytokine 2013;64:54-7.

7. Rodrigues FM, Coelho Neto GT, Menezes JG, et al. Expression of Foxp3, TGF- $\beta$ and IL-10 in American cutaneous leishmaniasis lesions. Arch Dermatol Res 2014;306:163-71.

8. Qu N, Xu M, Mizoguchi I, et al. Pivotal roles of T-helper 17-related cytokines, IL-17, IL-22, and IL23, in inflammatory diseases. Clin Dev Immunol 2013;2013:968549.

9. Cavani A, Pennino D, Eyerich K. Th17 and Th22 in skin allergy. Chem Immunol Allergy 2012;96:39-44.

10. Ma L, Xue HB, Guan XH, et al. Possible role of Th17 cells and IL-17 in the pathogenesis of atopic dermatitis in northern China. J Dermatol Sci 2012;68:66-8.

11. Hwang JS, Kim JE, Yu YB, et al. Modulation of experimental atopic dermatitis by topical application of Gami-Cheongyeul-Sodok-Eum. BMC Complement Altern Med 2013;13:312.

12. Pople PV, Singh KK. Targeting tacrolimus to deeper layers of skin with improved safety for treatment of atopic dermatitis-Part II: in vivo assessment of dermatopharmacokinetics, biodistribution and efficacy. Int J Pharm 2012;434:70-9.

13. Ou LS, Huang JL. Cellular aspects of atopic dermatitis. Clin Rev Allergy Immunol 2007;33:191-8.

14. Liu S, Zhang S, Jiang H, et al. Co-expression of AQP3 and AQP5 in esophageal squamous cell carcinoma correlates 
with aggressive tumor progression and poor prognosis. Med Oncol 2013;30:636.

15. Tan Q, Yang H, Liu EM, et al. Establishing a Role for Interleukin-17 in Atopic Dermatitis-Related Skin Inflammation. J Cutan Med Surg 2017;21:308-15.

16. Leonardi S, Cuppari C, Manti S, et al. Serum interleukin 17 , interleukin 23 , and interleukin 10 values in children with atopic eczema/dermatitis syndrome (AEDS): association with clinical severity and phenotype. Allergy Asthma Proc 2015;36:74-81.

17. Hayashida S, Uchi H, Moroi Y, et al. Decrease in circulating Th17 cells correlates with increased levels of CCL17, IgE and eosinophils in atopic dermatitis. J Dermatol Sci 2011;61:180-6.

18. Ezzedine K, Shourick J, Merhand S, et al. Impact of Atopic Dermatitis in Adolescents and their Parents: A French Study. Acta Derm Venereol 2020;100:adv00294.

19. Yang HJ, Min TK, Lee HW, et al. Efficacy of Probiotic Therapy on Atopic Dermatitis in Children: A Randomized, Double-blind, Placebo-controlled Trial. Allergy Asthma Immunol Res 2014;6:208-15.

20. Wu YJ, Wu WF, Hung CW, et al. Evaluation of efficacy and safety of Lactobacillus rhamnosus in children aged 4-48 months with atopic dermatitis: An 8-week, doubleblind, randomized, placebo-controlled study. J Microbiol Immunol Infect 2017;50:684-92.

21. Woo SI, Kim JY, Lee YJ, et al. Effect of Lactobacillus sakei supplementation in children with atopic eczemadermatitis syndrome. Ann Allergy Asthma Immunol 2010;104:343-8.

22. Torii S, Torii A, Itoh K, et al. Effects of oral administration of Lactobacillus acidophilus L-92 on the symptoms and serum markers of atopic dermatitis in children. Int Arch

Cite this article as: Mao Y, Yang C, Tang L, Liu G, Cheng L, Chen M. Increased expression of T helper 17 cells and interleukin-17 in atopic dermatitis: a systematic review and meta-analysis. Ann Palliat Med 2021;10(12):12801-12809. doi: 10.21037/apm-21-3590
Allergy Immunol 2011;154:236-45.

23. Hernandez-Mir G, Raphael I, Revu S, et al. The Alzheimer's Disease-Associated Protein BACE1 Modulates T Cell Activation and Th17 Function. J Immunol 2019;203:665-75

24. Shaw TE, Currie GP, Koudelka CW, et al. Eczema prevalence in the United States: data from the 2003 National Survey of Children's Health. J Invest Dermatol 2011;131:67-73.

25. Hidaka T, Ogawa E, Kobayashi EH, et al. The aryl hydrocarbon receptor AhR links atopic dermatitis and air pollution via induction of the neurotrophic factor artemin. Nat Immunol 2017;18:64-73.

26. Kim SR, Choi HS, Seo HS, et al. Oral administration of herbal mixture extract inhibits 2,4-dinitrochlorobenzeneinduced atopic dermatitis in BALB/c mice. Mediators Inflamm 2014;2014:319438.

27. Lee KH, Kim HJ, Kim HB, et al. Hizikia fusiformis fractions successfully improve atopic dermatitis indices in anti-CD3-stimulated splenocytes and 2,4-dinitrochlorobenzene-treated BALB/c mice. J Pharm Pharmacol 2014;66:466-76.

28. Watcharanurak K, Nishikawa M, Takahashi Y, et al. Regulation of immunological balance by sustained interferon- $\gamma$ gene transfer for acute phase of atopic dermatitis in mice. Gene Ther 2013;20:538-44.

29. Neumann C, Gutgesell C, Fliegert F, et al. Comparative analysis of the frequency of house dust mite specific and nonspecific Th1 and Th2 cells in skin lesions and peripheral blood of patients with atopic dermatitis. J Mol Med (Berl) 1996;74:401-6.

(English Language Editor: J. Teoh) 